\title{
Visual evoked Potential (VEP): Comparative study of physiological variation in children below 5 years and adults beyond 50 Years
}

\author{
Wadhera $\mathbf{J}^{1}$, Dudhmal $\mathbf{V}^{2}$ \\ ${ }^{1}$ Dr Jyoti Wadhera, Assistant Professor, Department of Physiology, ${ }^{2}$ Dr Vandana Dudhmal, Associate Professor, Department \\ of Physiology. Both are affiliated with KD Medical College Hospital and Research Center, Mathura, UP, India
}

Address for correspondence: Dr Jyoti Wadhera, Email: jyotiwadhera@ gmail.com

\begin{abstract}
Introduction: Visual evoked Potential is the electrical potential difference recorded from the surface of scalp in response to Visual stimuli. It represents a resultant response of cortical as well as subcortical areas to photostimulation. Although various studies have been done on visual evoked potential but there are few studies from India only. Therefore this study was planned to compare visual evoked potentials by recording battery of $\mathrm{N}_{70}, \mathrm{P}_{100} \& \mathrm{~N}_{155}$ waveform in children and adults beyond 50 years. Methods: Present study was conducted in department of Physiology of Tertiary care teaching hospital. 50 healthy patients were included in two groups, below 5 years and beyond 50 years. Visual evoked Potential has been recorded and their physiological Variation has been observed. Results: In our study on comparison between children and adults beyond 50 years there were no differences in amplitude and latency of N 70 and N155 waves observed. P100 latencies have shown statistically significant differences in amplitude and latencies although no differences in duration war observed. Conclusion: It is important that physiological variation should be kept in mind whenever we are making any interpretations. The changes in P100 with age may reflect senile changes in eye and optic nerve especially beyond 60 years of age.
\end{abstract}

Key words: Visual evoked Potential, $\mathrm{N}_{70}$ latency in adults, $\mathrm{P}_{100}$ amplitude in adults.

\section{Introduction}

The visual evoked potential is a gross electrical signal recorded from occipital cortex in response to a systematic change in some visual event such as flashing a light or an alternating checkered pattern. It represents a resultant response of cortical as well as subcortical areas to photostimulation [1]. It was first observed by Adrian and Mathews that fleshing light can induce a stimulus dependent change of brain activity [2]. The method currently provides the most sensitive means of detecting sub-clinical lesions of the optic nerve and may enable a diagnosis of multiple sclerosis to be made at earlier time. Under pathological conditions, visual evoked potential may show changes in amplitude, latency or waveform in one or more of its component.

VEP is primarily a reflection of activity originating in the central $3^{\circ}$ to $6^{\circ}$ of visual field, which is relayed to the surface of occipital lobe. The transient VEPs consist of series of waveforms of opposite polarity, the negative waveform is denoted as $\mathrm{N}$ and positive waveform is

Manuscript received: $4^{\text {th }}$ Jan 2015

Reviewed:9 $9^{\text {th }}$ Jan 2015

Author Corrected: $15^{\text {th }}$ Jan 2015

Accepted for Publication: $3^{\text {rd }}$ Feb 2015

International Journal of Medical Research and Review denoted as $\mathrm{P}$, which is followed by the approximate latency in millisec [3]. The commonly use waveform are $\mathrm{N}_{70}, \mathrm{P}_{100}$ and $\mathrm{N}_{155}$. The $\mathrm{P}_{100}$ waveform of VEP is generated in occipital cortex due to activation of primary visual cortex and also due to thalamocortical fibers.

VEP has been influenced by various physiological factors. Age has been reported to influence latency of $\mathrm{P}_{100}$ at a rate of $2.5 \mathrm{~ms} /$ decade after $5^{\text {th }}$ decade [4]. Infant and young children latency is longer and reaches adult value by 5-6 years. In infants amplitude is almost double of adult value [5]. Aging changes i.e. increase in latency attribute to increased conduction time in older subjects. Visual evoked potential amplitude tends to decrease with age, particularly during development. Male tend to show large aging effects than females. The results suggest that age related changes in human sensory system are not uniform but different in specific portions of these systems, different in particular echos of the lifespan and stronger in male than females [6].

Some other studies have revealed that major positive component $\mathrm{P}_{100}$ showed a shorter mean latency but higher mean amplitude for females than males. The age Available online at: www.ijmrr.in 378 | $\mathrm{P}$ a g e 
dependent increase in mean $\mathrm{P}_{100}$ latency was observed in female group but not in males. Study also suggests that gender is more important than age in affecting the $\mathrm{P}_{100}$ latency [7].

Although various studies have been done on visual evoked potential but there are few studies from India only. Therefore this study was planned to compare physiological variation of visual evoked potentials by recording battery of $\mathrm{N}_{70}, \mathrm{~N}_{100} \& \mathrm{~N}_{155}$ waveform in different age groups of population. We compare VEP patterns of young children with adults beyond 50 years of age.

\section{Material \& Methods}

Present study was conducted in department of Physiology of Tertiary care teaching hospital. 50 healthy patients were included in two groups

Group 1: 4 to 5 years of age

Group 2: Age beyond 50 years

Children below 4 years were excluded from study because they could not cooperate in maintaining fixation of eye at central point of checker board screen. This is an important pre requisite for recording pattern visual evoked potential [8].

Procedure of VEP recording: VEP were recorded in all subjects on a particular machine under similar laboratory

\section{Results}

TABLE 1: Showing Mean Value, Standard Deviation and Statistical Significance of Amplitude ( $\mu v)$ and Latency(ms) of $\mathrm{N}_{70}$ Wave form between Groups

\begin{tabular}{|c|c|c|c|c|c|c|}
\hline & \multicolumn{2}{|c|}{ Group I } & \multicolumn{2}{|c|}{ Group II } & \multicolumn{2}{|c|}{ P-value } \\
\hline & Left & Right & Left & Right & Left & Right \\
\hline \multicolumn{7}{|c|}{$\mathrm{N}_{70}$ Amplitude } \\
\hline Mean & 11.5 & 11.8 & 11.4 & 11.8 & $>0.05^{\mathrm{NS}}$ & $>0.05^{\mathrm{NS}}$ \\
\hline$\pm \mathrm{SD}$ & 2.97 & 2.75 & 2.89 & 2.11 & & \\
\hline \multicolumn{7}{|c|}{$\mathrm{N}_{70}$ Latency } \\
\hline Mean & 63.74 & 66.28 & 65.06 & 65.27 & $>0.05^{\mathrm{NS}}$ & $>0.05^{\mathrm{NS}}$ \\
\hline$\pm \mathrm{SD}$ & 4.29 & 4.97 & 2.94 & 4.06 & & \\
\hline
\end{tabular}

*statistically significant; NS-not significant

The table depicts that on comparison of Amplitude and latency of $\mathrm{N}_{70}$ wave in left and right eyes difference between the two groups were insignificant. conditions after they were acclimatize to the experimental conditions. The nature of the test was explained to them to allay fear and apprehension. The subject were informed about study and written and Verbal consent was taken.

Visual evoked Potential recordings were performed in a dark and sound attenuated room in a laboratory. The subject was asked to sit comfortably in front of the checkerboard pattern at an eye- screen distance of 100 $\mathrm{cm}$. The stimulus pattern was a black and white checkerboard displayed on a computer screen. The checks alternate from black/white at the rate of approximately twice per second. The subject was instructed to gaze at red color dot on the centre of checkerboard pattern. Each eye was tested separately. Every time when there was alteration in the pattern, the subject visual system generated an electrical response which was recorded using electrode [9].

For performing VEP test standard disc EEG electrode were used. These electrode were made of standard silver surface connected to a wire which was plugged into the machine [3].

The skin was prepared by degreasing. The recording electrode was place at highest point on the occiput using the conduction jelly or electrode paste. $\left[\mathrm{O}_{\mathrm{Z}}\right.$ electrode was located in the middle of the variation zone of calcarine fissure i.e. at the highest point on the occiput]. 


\section{Research Article}

TABLE 2: Showing Mean Value, Standard Deviation and Statistical Significance of Amplitude ( $\mu$ v), Latency (ms) and duration (ms) of $\mathrm{P}_{100}$ Waveform between Groups

\begin{tabular}{|c|c|c|c|c|c|c|}
\hline & \multicolumn{2}{|c|}{ Group I } & \multicolumn{2}{|c|}{ Group II } & \multicolumn{2}{|c|}{ P-value } \\
\hline & Left & Right & Left & Right & Left & Right \\
\hline \multicolumn{7}{|c|}{$\mathrm{P}_{100}$ Amplitude } \\
\hline Mean & 13.1 & 14.2 & 10.2 & 9.8 & $0.002 * *$ & $0.000 * * *$ \\
\hline$\pm \mathrm{SD}$ & 3.32 & 4.19 & 2.78 & 2.87 & & \\
\hline \multicolumn{7}{|c|}{$\mathrm{P}_{100}$ Latency } \\
\hline Mean & 94.66 & 93.44 & 95.87 & 96.84 & $>0.05^{\mathrm{NS}}$ & $>0.022 *$ \\
\hline$\pm \mathrm{SD}$ & 7.52 & 7.27 & 6.82 & 6.34 & & \\
\hline \multicolumn{7}{|c|}{$\mathrm{P}_{100}$ Duration } \\
\hline Mean & 76.2 & 81.0 & 79.2 & 79.8 & $>0.05^{\mathrm{NS}}$ & $>0.05^{\mathrm{NS}}$ \\
\hline$\pm \mathrm{SD}$ & 11.39 & 9.68 & 9.68 & 8.35 & & \\
\hline
\end{tabular}

*statistically significant; NS-not significant; **/***-highly significant

The table depicts that on comparison of Amplitude of $\mathrm{P}_{100}$ wave in both eyes difference between the two groups were highly significant. Although on comparison of duration and latency of $\mathrm{P}_{100}$ there were no statistically significant difference in children and adults beyond 50 years of age.

TABLE 3: Showing Mean Value, Standard Deviation and Statistical Significance of Amplitude ( $\mu v)$ and Latency(ms) of $\mathrm{N}_{155}$ Waveform between Groups

\begin{tabular}{|c|c|c|c|c|c|c|}
\hline & \multicolumn{2}{|c|}{ Group I } & \multicolumn{2}{|c|}{ Group II } & \multicolumn{2}{|c|}{ P-value } \\
\hline & Left & Right & Left & Right & Left & Right \\
\hline \multicolumn{7}{|c|}{$\mathrm{N}_{155}$ Amplitude } \\
\hline Mean & 12.4 & 13.2 & 10.6 & 11.6 & $>0.05^{\mathrm{NS}}$ & $>0.05^{\mathrm{NS}}$ \\
\hline$\pm \mathrm{SD}$ & 3.85 & 4.24 & 3.00 & 2.78 & & \\
\hline \multicolumn{7}{|c|}{$\mathrm{N}_{155}$ Latency } \\
\hline Mean & 154.48 & 157.5 & 152.68 & 155.47 & $>0.05^{\mathrm{NS}}$ & $>0.05^{\mathrm{NS}}$ \\
\hline$\pm \mathrm{SD}$ & 8.62 & 7.12 & 7.42 & 5.93 & & \\
\hline
\end{tabular}

*statistically significant; NS-not significant

The table depicts that on comparison of Amplitude and latency of $\mathrm{N}_{155}$ wave in left and right eyes; difference between the two groups were insignificant.

TABLE 4: Showing Mean Value, Standard Deviation and Statistical Significance of Amplitude ( $\mu$ v) and Latency (ms) of $\mathrm{N}_{70}$ Waveform between Males and Females of Group I

\begin{tabular}{|c|c|c|c|c|c|c|}
\hline & \multicolumn{2}{|l|}{ Male } & \multicolumn{2}{|c|}{ Female } & \multicolumn{2}{|c|}{ P-value } \\
\hline & Left & Right & Left & Right & Left & Right \\
\hline \multicolumn{7}{|c|}{$\mathrm{N}_{70}$ Amplitude } \\
\hline Mean & 10.38 & 10.76 & 12.7 & 12.91 & $0.049 *$ & $0.049 *$ \\
\hline$\pm \mathrm{SD}$ & 2.46 & 2.57 & 3.1 & 2.57 & & \\
\hline \multicolumn{7}{|c|}{$\mathrm{N}_{70}$ Latency } \\
\hline Mean & 61.79 & 66.83 & 65.85 & 65.68 & $0.014^{*}$ & $>0.05 \mathrm{NS}$ \\
\hline$\pm \mathrm{SD}$ & 3.97 & 5.2 & 3.68 & 4.85 & & \\
\hline
\end{tabular}

*statistically significant; NS-not significant

The data depicts that mean value for amplitude of $\mathrm{N}_{70}$ wave between male and female children in group 1 is statistically significant in both eyes. Latency is significantly different in left eye only. 


\section{Research Article}

TABLE 5: Showing Mean Value, Standard Deviation and Statistical Significance of Amplitude ( $\mu \mathrm{v})$, Latency(ms) and Duration (ms) of $\mathrm{P}_{100}$ Waveform Between Males and Females of Group I

\begin{tabular}{|c|c|c|c|c|c|c|}
\hline & \multicolumn{2}{|l|}{ Male } & \multicolumn{2}{|c|}{ Female } & \multicolumn{2}{|l|}{ P-value } \\
\hline & Left & Right & Left & Right & Left & Right \\
\hline \multicolumn{7}{|c|}{$\mathrm{P}_{100}$ Amplitude } \\
\hline Mean & 11.34 & 11.53 & 15.0 & 17.08 & $0.004 * *$ & $0.000 * * *$ \\
\hline$\pm \mathrm{SD}$ & 1.94 & 2.4 & 3.53 & 3.81 & & \\
\hline \multicolumn{7}{|c|}{$\mathrm{P}_{100}$ Latency } \\
\hline Mean & 93.43 & 92.16 & 95.98 & 94.82 & $>0.05^{\mathrm{NS}}$ & $>0.05^{\mathrm{NS}}$ \\
\hline$\pm \mathrm{SD}$ & 5.75 & 5.51 & 9.14 & 9.79 & & \\
\hline \multicolumn{7}{|c|}{$\mathrm{P}_{100}$ Duration } \\
\hline Mean & 75.0 & 79.61 & 77.5 & 82.5 & $>0.05^{\mathrm{NS}}$ & $>0.05^{\mathrm{NS}}$ \\
\hline$\pm \mathrm{SD}$ & 12.24 & 11.2 & 10.76 & 7.83 & & \\
\hline
\end{tabular}

*statistically significant; NS-not significant; **/***-highly significant

The data depicts that mean value for amplitude of P100 wave between male and female children in group 1 is statistically significant in both eyes.

TABLE 6: Showing Mean Value, Standard Deviation and Statistical Significance of Amplitude ( $\mu v)$ and Latency(ms) of $\mathrm{N}_{155}$ Waveform between Males and Females of Group I

\begin{tabular}{|c|c|c|c|c|c|c|}
\hline & \multicolumn{2}{|l|}{ Male } & \multicolumn{2}{|c|}{ Female } & \multicolumn{2}{|l|}{ P-value } \\
\hline & Left & Right & Left & Right & Left & Right \\
\hline \multicolumn{7}{|c|}{$\mathrm{N}_{155}$ Amplitude } \\
\hline Mean & 11.53 & 12.88 & 13.33 & 13.54 & $>0.05^{\mathrm{NS}}$ & $>0.05^{\mathrm{NS}}$ \\
\hline$\pm \mathrm{SD}$ & 4.15 & 5.18 & 3.42 & 3.10 & & \\
\hline \multicolumn{7}{|c|}{$\mathrm{N}_{155}$ Latency } \\
\hline Mean & 152.03 & 156.24 & 157.15 & 158.87 & $>0.05^{\mathrm{NS}}$ & $>0.05^{\mathrm{NS}}$ \\
\hline$\pm \mathrm{SD}$ & 5.49 & 7.70 & 10.69 & 6.49 & & \\
\hline
\end{tabular}

*statistically significant; NS-not significant

The data depicts that mean value for amplitude and latency of $\mathrm{N}_{155}$ wave between male and female children in group 1 is statistically non-significant in both eyes.

TABLE 7: Showing Mean Value, Standard Deviation and Statistical Significance of Amplitude ( $\mu v)$ and Latency(ms) of $\mathrm{N}_{70}$ Waveform between Males and Females of Group 2

\begin{tabular}{|c|c|c|c|c|c|c|}
\hline & \multicolumn{2}{|c|}{ Male } & \multicolumn{2}{|c|}{ Female } & \multicolumn{2}{|c|}{ P-value } \\
\hline & Left & Right & Left & Right & Left & Right \\
\hline \multicolumn{7}{|c|}{$\mathrm{N}_{70}$ Amplitude } \\
\hline Mean & 10.62 & 11.04 & 12.11 & 12.50 & $>0.05^{\mathrm{NS}}$ & $>0.05^{\mathrm{NS}}$ \\
\hline$\pm \mathrm{SD}$ & 3.39 & 2.25 & 2.24 & 1.76 & & \\
\hline \multicolumn{7}{|c|}{$\mathrm{N}_{70}$ Latency } \\
\hline Mean & 64.71 & 65.65 & 65.39 & 64.92 & $>0.05^{\mathrm{NS}}$ & $>0.05^{\mathrm{NS}}$ \\
\hline$\pm \mathrm{SD}$ & 3.43 & 4.41 & 2.52 & 3.86 & & \\
\hline
\end{tabular}

*statistically significant; NS-not significant

The data depicts that mean value for amplitude and latency of $\mathrm{N}_{70}$ wave between male and female patients in group 2 is statistically non-significant in both eyes 


\section{Research Article}

TABLE 8: Showing Mean Value, Standard Deviation and Statistical Significance of Amplitude ( $\mu \mathrm{v})$, Latency(ms) and duration (ms) of $\mathrm{P}_{100}$ Waveform between Males and Females of Group 2

\begin{tabular}{|c|c|c|c|c|c|c|}
\hline & \multicolumn{2}{|c|}{ Male } & \multicolumn{2}{|c|}{ Female } & \multicolumn{2}{|c|}{ P-value } \\
\hline & Left & Right & Left & Right & Left & Right \\
\hline \multicolumn{7}{|c|}{$\mathrm{P}_{100}$ Amplitude } \\
\hline Mean & 8.33 & 7.91 & 11.92 & 11.53 & $0.000 * * *$ & $0.001 * *$ \\
\hline$\pm \mathrm{SD}$ & 2.68 & 2.34 & 1.49 & 2.17 & & \\
\hline \multicolumn{7}{|c|}{$\mathrm{P}_{100}$ Latency } \\
\hline Mean & 98.62 & 99.78 & 93.34 & 94.12 & $>0.05^{\mathrm{NS}}$ & $>0.022^{*}$ \\
\hline$\pm \mathrm{SD}$ & 6.01 & 4.19 & 6.75 & 6.90 & & \\
\hline \multicolumn{7}{|c|}{$\mathrm{P}_{100}$ Duration } \\
\hline Mean & 78.75 & 80.0 & 79.61 & 79.61 & $>0.05^{\mathrm{NS}}$ & $>0.05^{\mathrm{NS}}$ \\
\hline$\pm \mathrm{SD}$ & 11.3 & 9.77 & 7.20 & 7.20 & & \\
\hline
\end{tabular}

*statistically significant; NS-not significant; $* * / * * *$-highly significant

The data depicts that mean value for amplitude of $\mathrm{P}_{100}$ wave between male and female patients in group 2 is statistically significant in both eyes.

TABLE 9: Showing Mean Value, Standard Deviation and Statistical Significance of Amplitude ( $\mu \mathrm{v})$ and Latency (ms) of $\mathrm{N}_{155}$ Waveform between Males and Females of Group 2

\begin{tabular}{|c|c|c|c|c|c|c|}
\hline & \multicolumn{2}{|c|}{ Male } & \multicolumn{2}{|c|}{ Female } & \multicolumn{2}{|c|}{ P-value } \\
\hline & Left & Right & Left & Right & Left & Right \\
\hline \multicolumn{7}{|c|}{$\mathrm{N}_{155}$ Amplitude } \\
\hline Mean & 8.54 & 10.0 & 12.5 & 13.07 & $0.000 * * *$ & $0.003 * *$ \\
\hline$\pm \mathrm{SD}$ & 2.91 & 2.82 & 1.44 & 1.81 & & \\
\hline \multicolumn{7}{|c|}{$\mathrm{N}_{155}$ Latency } \\
\hline Mean & 152.85 & 157.64 & 152.52 & 153.47 & $>0.05^{\mathrm{NS}}$ & $>0.05^{\mathrm{NS}}$ \\
\hline$\pm \mathrm{SD}$ & 8.38 & 7.46 & 6.75 & 3.19 & & \\
\hline
\end{tabular}

*statistically significant; NS-not significant; **/***-highly significant

The data depicts that differences in mean value for amplitude of $\mathrm{N}_{100}$ wave between male and female patients in group 2 is statistically significant in both eyes.

\section{Discussion}

In our study Amplitude of $\mathrm{N}_{155}$ and $\mathrm{P}_{100}$ were more in females especially in age beyond 50 years. In pediatric population Amplitude was more in N70 and P100 waves in female patients. Other study conducted by Armstrong Ra et al in age between 15-86 years has shown that there was increase in latency of the positive major component P100 increased with age. The changes in P100 with age may reflect senile changes in eye and optic nerve e.g. senile miosis, degenerative changes in retina or geniculostriate deficit [10].

In another study visual evoked potentials were performed in normal subjects in $4^{\text {th }}$ to $9^{\text {th }}$ decade. VEP latency was found to increase with age but no variation with gender observed. However VEP amplitude showed no variation with agebut lower values in males were found as compared to females [11].
Pattern reversal evoked potentials were recorded from people whose ages ranged from 4 to 90 years. Dramatic decrease in PREP amplitudes occurred between childhood and adolescence. These changes were more prominent in females. Following adolescence there were no significant changes in amplitudes even to old age. Latencies in other hand have been shown to change most dramatically between adulthood and old age. PREP amplitudes and latencies, therefore appear to provide different and unique information regarding development and aging [12].

In another study latencies were found to decreases during maturation, stabilize across early adulthood then begin to increase sometimes after late 20 s. there were minima gender differences in latencies during development but males tend to have longer latencies than females during adulthood. Across the lifespan, amplitudes were lager for females [13]. 
A study conducted in age group of 8- 70 years to analyze the relation between VEPs and gender. No effect of gendr on P100 latency was found [14].

It was concluded that P100 latency prolonged with aging particularly after age of 55 years while P100 amplitude has been gradually decreased during the life. During aging senile changes in the eyes and optic nerve (senile miosis, senile degenerative changes) can be reflected to the changes in VEP [15].

\section{VEP in Elderly Population}

Pattern shift visual evoked potentials were obtained in elderly subject. The combined eye mean P100 latency in elderly was significant longer than young subjects [16]. Elderly females had shorter $\mathrm{P}_{100}$ and $\mathrm{N}_{150}$ latencies and greater $\mathrm{P}_{100}-\mathrm{N}_{150}$ amplitude. The $\mathrm{N} 150$ latency differences were significant even when $\mathrm{P}_{100}$ latency effect were partially out statistically. The result provide evidences that in the elderly gender differences in PREP amplitude reflects factor specific to CNS processing of visual stimuli rater than global CNS anatomical or physiological factors and that gender differences in $\mathrm{P}_{100}$ latency reported in younger group were also present in the elderly [17].

In our study on comparison between children and adults beyond 50 years there were no differences in amplitude and latency of $\mathrm{N}_{70}$ and $\mathrm{N}_{155}$ waves. $\mathrm{P}_{100}$ latencies have shown statistically significant differences in amplitude and latencies although no differences in duration war observed.

On comparison between male and female child there were significant differences between amplitude of $\mathrm{P}_{100}$. In adults beyond 50 years of age significant differences between male and female were observed in $\mathrm{P}_{100}$ and $\mathrm{N}_{155}$ waves.

\section{Conclusion}

VEP varies with age. It is important that physiological variation should be kept in mind whenever we are making any interpretations. The changes in $\mathrm{P}_{100}$ with age may reflect senile changes in eye and optic nerve especially beyond 60 .

Funding: Nil, Conflict of interest: None initiated. Permission from IRB: Yes

\section{References}

1. Jain AK, Editor. Neuro- electrodiadnostic techniques. visual evoked potentials.In : Manual of Practical
Physiology. $1^{\text {st }}$ Edition,Arya Publication, New Delhi;2003.p.261-2.

2. Adrian ED, Matthews R . The action of light on the eye: Part II. The processes involved in retinal excitation. J Physiol. 1927 Dec 29;64(3):279-301.

3. Misra UK, Kalita J. visual evoked PotentialAnatomical basis of visual evoked Potential. Clinical Neurophysiology, $1^{\text {st }}$ edition, New Delhi: Elsevier,1998;p.311-324.

4. Stockard JE, Stockard JJ, Westmoreland BF, Corfits JL. Brainstem auditory-evoked responses. Normal variation as a function of stimulus and subject characteristics.. Arch Neurol. 1979 Dec;36(13):823-31.

5. Jain AK, Editor. Neuro- electrodiadnostic techniques. visual evoked potentials.In : Manual of Practical Physiology. $1^{\text {st }}$ Edition,Arya Publication, New Delhi;2003.p.261-2.

6. Allison T, Hume AL, Wood CC, Goff WR. Developmental and aging changes in somatosensory, auditory and visual evoked potentials. Electroencephalogr Clin Neurophysiol. 1984 Jul;58(1):14-24.

7. Chu NS. Pattern-reversal visual evoked potentials: latency changes with gender and age. Clin Electroencephalogr. 1987 Jul;18(3):159-62.

8. Tandon OP, Ram D. Visual evoked responses to pattern reversal in children. Indian J Physiol Pharmacol. 1991 Jul;35(3):175-9.

9. Mukartihal GB, Radhakrishnan S, Reddy M, Ayyar SSK. Design and development of visual evoked potentials recording system for diagnosis of optic nerve diseases. J Instrum soc India 2006;36(4):227-34

10. Armstrong RA, Slaven A, Harding GF. The influence of age on the pattern and flash visual evoked magnetic response (VEMR). Ophthalmic Physiol Opt. 1991 Jan;11(1):71-5.

11. Mitchell KW, Howe JW, Spencer SR. Visual evoked potentials in the older population: age and gender effects. Clin Phys Physiol Meas. 1987 Nov;8(4):317-24.

12. Snyder EW, Dustman RE, Shearer DE. Pattern reversal evoked potential amplitudes: life span changes. Electroencephalogr Clin Neurophysiol. 1981 Nov;52(5):429-34. 


\section{Research Article}

13. Emmerson-Hanover $\mathrm{R}^{1}$, Shearer DE, Creel DJ, Dustman RE. Pattern reversal evoked potentials: gender differences and age-related changes in amplitude and latency. Electroencephalogr Clin Neurophysiol. 1994 Mar;92(2):93-101.

14. Sobieszczańska M, Pilecki W, Borodulin-Nadzieja L, Kałka D, Janocha A, Salomon E. The effect of the gender of the examined subjects on the course of the visual potentials evoked by the checker board pattern stimulation. Klin Oczna. 1998;100(5):269-73.
15. Aleksić P, Raicević R, Stamenković M, Djordjević D. Effect of aging on visual evoked potentials. Vojnosanit Pregl. 2000 May-Jun;57(3):297-302. Serbian.

16. Verma NP, Kooi KA. Gender factor in longer P100 latency of elderly persons. Electroencephalogr Clin Neurophysiol. 1984 Sep;59(5):361-5.

17. Fein G, Brown FF. Gender differences in pattern reversal evoked potentials in normal elderly. Psychophysiology. 1987 Nov;24(6):683-90

\section{How to cite this article?}

Wadhera J, Dudhmal V. Visual evoked Potential (VEP): Comparative study of physiological variation in children below 5 years and adults beyond 50 Years. Int J Med Res Rev 2015;3(4):378-384. doi: 10.17511/ijmrr.2015.i4.071. 